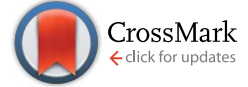

Cite this: RSC Adv., 2016, 6, 75844

\title{
Facile high-yield synthesis of unsymmetric end-off compartmental double Schiff-base ligands: easy access to mononuclear precursor and unsymmetric dinuclear complexes $\uparrow$
}

\begin{abstract}
Markus Schmidt, Helmar Görls and Winfried Plass*
A straightforward and easy to handle two-step synthetic route for unsymmetric double Schiff-base ligands is presented. The isolated intermediate single Schiff-base precursor ligands $\mathrm{H}_{2} \mathrm{Sc}$-difo and $\mathrm{H}_{2} \mathrm{tsc}$-difo were derived by condensation of 2,6-diformyl-4-methylphenol with semicarbazide and thiosemicarbazide, respectively. Further reaction of the precursor ligands with different amine components, including both aliphatic and aromatic examples, allows the synthesis of ditopic unsymmetric double Schiff-base ligands in high yields and purity. As aliphatic cases we used (2-aminoethyl)bis(2-pyridylmethyl)-amine $\left(\mathrm{H}_{2} \mathrm{SC}-\right.$ hydra and $\mathrm{H}_{2}$ tsc-hydra) and 2-(aminomethyl)-pyridine $\left(\mathrm{H}_{2} \mathrm{sc}\right.$-ampy and $\mathrm{H}_{2} \mathrm{tsc}$-ampy), whereas 2aminophenol was used as an aromatic sample $\left(\mathrm{H}_{3} \mathrm{Sc}\right.$-amph and $\mathrm{H}_{3} \mathrm{tsc}$-amph). The overall synthetic route allows for the preparation of the employed ligands in large scale. To explore the coordination capabilities of the reported ligand systems a mononuclear nickel(॥) complex [Ni(tsc-difo)PPh $\mathrm{Ph}_{3}$ and a homodinuclear zinc(II) complex $\left[\mathrm{Zn}_{2}(\mathrm{tsc}-\mathrm{hydra})(\mathrm{OAc})_{2}\right]$ were synthesized with the single Schiff-base precursor ligand $\mathrm{H}_{2}$ tsc-difo and the double Schiff-base ligands $\mathrm{H}_{2}$ tsc-hydra, respectively. Both complexes crystallized in the monoclinic space group $P 2_{1} / n$. For [Ni(tsc-difo)PPh $h_{3}$ a square-planar geometry is found for nickel(॥) ion with $\mathrm{H}_{2}$ tsc-difo acting as a tridentate ligand. Whereas the structure of complex $\left[\mathrm{Zn}_{2}(\mathrm{tsC}\right.$ hydra) $(\mathrm{OAc})_{2}$ ] reveals two zinc(II) ions in distinctly different coordination geometry, one in distorted octahedral coordination located in the bispyridine based binding pocket with $\left[\mathrm{N}_{4} \mathrm{O}_{2}\right]$ donor set and the other zinc(II) ion in a distorted square-pyramidal coordination given by the thiosemicarbazone based binding pocket with $\left[\mathrm{NO}_{3} \mathrm{~S}\right]$ donor set.
\end{abstract}

Received 30th June 2016

Accepted 2nd August 2016

DOI: 10.1039/c6ra16870a

www.rsc.org/advances

\section{Introduction}

Bimetallic active sites are widely spread in metalloenzymes of numerous biological systems for which examples have been isolated and structurally characterized. ${ }^{1,2}$ As a prominent feature for such active sites the metal centers are usually embedded in distinctly different binding pockets. ${ }^{3}$ The resulting lack of symmetry can be due to different donor atoms involved as well as the coordination number and geometry at the metal sites. ${ }^{4}$ This enables the two metal centers to perform different tasks within the enzymatic activity. Examples of such metalloenzymes range from homodinuclear cases like urease ${ }^{5,6}$ $\left(\mathrm{Ni}_{2}\right)$, metallo- $\beta$-lactamase ${ }^{7}\left(\mathrm{Zn}_{2}\right)$, and the dioxygen carrier hemerythrin ${ }^{8}\left(\mathrm{Fe}_{2}\right)$ towards heterobimetallic metallobiosites as

Institut für Anorganische und Analytische Chemie, Friedrich-Schiller-Universität Jena, Humboldtstrasse 8, 07743 Jena, Germany. E-mail: sekr.plass@uni-jena.de; Fax: +49 3641 948132; Tel: +493641948130

$\dagger$ Electronic supplementary information (ESI) available. CCDC numbers 1043774 $\left.\left(\left[\mathrm{Zn}_{2} \text { (tsc-hydra)(OAc) }\right)_{2}\right]\right)$ and 1048856 ([Ni(tsc-difo) $\left.\left.\mathrm{PPh}_{3}\right]\right)$. For $\mathrm{ESI}$ and crystallographic data in CIF or other electronic format see DOI: 10.1039/c6ra16870a in purple acid phosphatases ${ }^{9}(\mathrm{Fe} / \mathrm{Zn})$, copper-zinc superoxide dismutase $^{10}(\mathrm{Cu} / \mathrm{Zn})$, and arylamine oxygenase $\operatorname{AurF}^{11,12}(\mathrm{Fe} /$ $\mathrm{Mn})$. Moreover, bimetallic complexes also play an important role in catalytic processes and novel abiotic molecule transformations. The concept of cooperative reactivity based on bimetallic catalysts ${ }^{13-15}$ has lead to interesting applications such as asymmetric rearrangements, ${ }^{16}$ ring opening reactions, ${ }^{17}$ hydroalkoxylation of alkynes, ${ }^{18}$ palladium-assisted $\mathrm{C}-\mathrm{X}$ bond formation ${ }^{19}$ and polymerizations. ${ }^{20,21}$

Over the past decades compartmental ligands capable of coordinating multiple metal ions have been an intense area of research. ${ }^{22,23}$ Among these supporting scaffolds unsymmetric ligands deliberately providing unequal binding pockets for metal ions are of particular interest. ${ }^{24-29}$ Several approaches have been proposed to synthesize such unsymmetric ligands that utilize multi-step synthetic routes typically starting from predesigned unsymmetric bridging units. ${ }^{30-44}$ Although Schiffbase ligands have been found to offer excellent potential as their coordination ability and applications of related complexes are concerned, their utilization in the design of unsymmetric ditopic ligand systems is still limited. ${ }^{45,46}$ 
<smiles>Cc1cc(C=O)c(O)c(C=O)c1</smiles><smiles>[3H][14C]([14CH3])N</smiles>
$R^{1}$<smiles>Cc1cc(C=N)c(O)c(C=O)c1</smiles><smiles>[R]N=Cc1cc(C)cc(C=N[R])c1O</smiles>

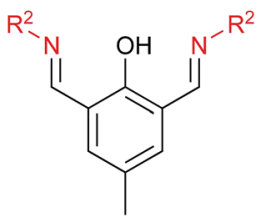

Fig. 1 General scheme for the synthesis of unsymmetric double Schiff bases indicating the possible formation of symmetric side products.

In this context we have reported a versatile synthetic approach towards double Schiff-base ligands which is based on stepwise Schiff-base condensation utilizing the symmetric dicarbonyl bridge 2,6-diformyl-4-methylphenol (dfc) and two different primary amines (see Fig. 1). ${ }^{47}$ The related end-off compartmental ligands systems can be utilized for directed synthesis of heterobimetallic complexes. ${ }^{48}$ However, the crucial step in the synthesis of these double Schiff-base ligands is the separation of the monocarbonyl precursor ligand from the symmetric side products by size-exclusion chromatography which has some drawbacks. Primarily this considerably limits the scale of reaction to the lower millimolar range and due to the prolonged times needed during reaction and separation this can lead to a small portion of undesired re-symmetrization due to imine metathesis. ${ }^{49}$

Here we describe a straightforward and easy to handle large scale synthetic approach towards unsymmetric double Schiff bases via isolated intermediate single Schiff-base precursors based on thiosemicarbazide and semicarbazide as amine components. Schiff bases containing the latter are not only known for their good coordination abilities ${ }^{50}$ but also for the formation of complexes with antibacterial, antiviral, anticancer, and other biological properties..$^{51-53}$

\section{Experimental}

\section{Instrumentation}

The NMR spectra were measured with Bruker Avance $400 \mathrm{MHz}$ and $600 \mathrm{MHz}$ spectrometers. For recording the IR spectra a Bruker IFS55/Equinox spectrometer equipped with a diamond ATR unit was used. The UV/Vis data were collected on a Cary
Varian 5000 UV/Vis/NIR spectrometer. Mass spectra were carried out with the help of a MAT95XL Finnigan instrument. The elemental analyses were determined with a VARIO EL III and LECO CHN/932 elemental analyzers.

\section{Materials}

The starting materials 2,6-diformylcresol (dfc) ${ }^{54}$ and (2-aminoethyl)bis(2-pyridylmethyl)amine ${ }^{55}$ were prepared according to the methods described in literature. All other chemicals were purchased from commercial suppliers and applied as received, except for the solvents which were purified and distilled prior to use.

\section{Synthesis of proligands}

[(3-Formyl-2-hydroxy-5-methylphenyl)methylidene]aminothiourea ( $\mathbf{H}_{2}$ tsc-difo). 2,6-Diformylcresol (dfc, $6.2 \mathrm{~g}, 37.8 \mathrm{mmol}$ ) was dissolved in acetonitrile $(100 \mathrm{~mL})$ and placed in a singleneck round-bottom flask. Subsequently a fritted glass filter with pressure equalizer was filled with thiosemicarbazide (tsc, $2.24 \mathrm{~g}, 24.6 \mathrm{mmol}$ ) and mounted on the round-bottom flask. A reflux condenser was placed on top of this assembly and linked to a membrane pump equipped with a pressure control unit (see Fig. $\mathrm{S} 1 \dagger$ ). The pressure in the system was automatically maintained at about 240 mbar and the reaction solution heated under reflux (at about $40{ }^{\circ} \mathrm{C}$ ). The reaction mixture turned immediately yellow and after a few minutes a yellow precipitate started to form. The reaction is finished when all tsc was eluted from the fritted glass. The proligand was separated from the reaction mixture by filtration, washed a few times with dichloromethane and dried in vacuo at $45{ }^{\circ} \mathrm{C}$. Yield: $5.43 \mathrm{~g}$ (93\%). Anal. calcd for $\mathrm{C}_{10} \mathrm{H}_{11} \mathrm{~N}_{3} \mathrm{O}_{2} \mathrm{~S}(M=237.28)$ : C, 50.6; H, 4.7; $\mathrm{N}, 17.7 ; \mathrm{S}, 13.5 \%$. Found: C, 50.7; H, 4.6; N, 17.9; S, $13.4 \% .{ }^{1} \mathrm{H}$ NMR (400 MHz, DMSO-d ${ }_{6}, \delta$ in ppm, see Fig. S2 $\left.\dagger\right): 2.30(\mathrm{~s}, 3 \mathrm{H}$, $\mathrm{CH}_{3}, \mathrm{H}-9$ ), 7.58 (s, 1H, H-6), 8.08 (s, 1H, NH ${ }_{2}$ ), 8.19 (s, 1H, H-4), $8.24\left(\mathrm{~s}, 1 \mathrm{H}, \mathrm{NH}_{2}\right), 8.35(\mathrm{~s}, 1 \mathrm{H}, \mathrm{HC}=\mathrm{N}, \mathrm{H}-2), 10.03(\mathrm{~s}, 1 \mathrm{H}, \mathrm{HC}=\mathrm{O}$, $\mathrm{H}-10), 10.91$ (s, 1H, OH), 11.51 (s, 1H, NH). ${ }^{13} \mathrm{C}\left\{{ }^{1} \mathrm{H}\right\}$ NMR (100 MHz, DMSO-d ${ }_{6}, \delta$ in ppm, see Fig. S2 $\dagger$ ): 19.7 (C9), 121.8 (C7), 122.1 (C3), 129.1 (C5), 134.2 (C4), 134.3 (C6), 137.1 (C2), 156.7 (C8), 177.9 (C1), 195.7 (C10). MS (DEI, $m / z$, rel. int. in \%): 237 (70, $\left.\mathrm{M}^{+}\right), 162$ (100), 133 (32), 106 (30), 76 (52). FT-IR: see Fig. S3. $\dagger$

[(3-Formyl-2-hydroxy-5-methylphenyl)methylidene]aminourea ( $\mathbf{H}_{2}$ sc-difo). For the synthesis of $\mathrm{H}_{2}$ sc-difo the same experimental setup as for $\mathrm{H}_{2}$ tsc-difo was applied. 2,6-Diformylcresol (dfc, $6.0 \mathrm{~g}$, $36.6 \mathrm{mmol}$ ) was dissolved in dichloromethane $(100 \mathrm{~mL})$. To this solution was added triethylamine $(6.0 \mathrm{~g}, 59.3 \mathrm{mmol})$ and the solution turned immediately dark red. The semicarbazide hydrochloride $(3.0 \mathrm{~g}, 26.9 \mathrm{mmol})$ was placed on the fritted glass filter which was mounted on the round-bottom flask. The reaction mixture was heated to reflux and kept at this temperature throughout. During the reaction a yellowish precipitate was formed. After all solid starting material was eluted from the fritted glass filter the reaction mixture was cooled to room temperature. The precipitate was filtered off, washed several times dichloromethane and subsequently dried in vacuo under reduced pressure. Yield: $4.47 \mathrm{~g}(74 \%)$. Anal. calcd for $\mathrm{C}_{10} \mathrm{H}_{11} \mathrm{~N}_{3} \mathrm{O}_{3}$ $(M=221.21)$ : C, 54.3; H, 5.0; N, 19.0\%. Found: C, 54.0; H, 5.1; N, 
19.2\%. ${ }^{1} \mathrm{H}$ NMR (400 MHz, DMSO-d ${ }_{6}, \delta$ in ppm, see Fig. S4 $\dagger$ ): 2.29 (s, 3H, $\left.\mathrm{CH}_{3}, \mathrm{H}-9\right), 6.52$ (s, 2H, NH $\mathrm{NH}_{2}, 7.52$ (s, 1H, H-6), 7.99 (s, 1H, $\mathrm{H}-4), 8.13$ (s, 1H, HC=N, H-2), 10.09 (s, 1H, HC=O, H-10), 10.38 (s, 1H, NH), 11.13 (s, 1H, OH). ${ }^{13} \mathrm{C}\left\{{ }^{1} \mathrm{H}\right\}$ NMR (100 MHz, DMSO-d ${ }_{6}$, $\delta$ in ppm, see Fig. S4†): 19.7 (C9), 121.9 (C7), 122.2 (C3), 128.8 (C5), 132.3 (C6), 134.1 (C4), 135.5 (C2), 156.3 (C1), 156.4 (C8), 194.6 (C10). MS (DEI, $m / z$, rel. int. in \%): 237 (98, M $^{+}$), 193 (67), 162 (100), 133 (82), 106 (57). FT-IR: see Fig. S5. $\dagger$

\section{Synthesis of double Schiff bases}

A solution of (2-aminoethyl)bis(2-pyridylmethyl)amine in methanol ( $400 \mathrm{~mL})$ was added dropwise over a period of $24 \mathrm{~h}$ to a yellow suspension of one equivalent of the corresponding proligand in methanol $(100 \mathrm{~mL})$. The reaction mixture immediately turned to an orange to red color and became a clear solution at the end of the addition. Subsequently the solvent was removed under reduced pressure at a temperature of $40{ }^{\circ} \mathrm{C}$ by means of a rotary evaporator. The residual orange-red solid was washed several times with diethyl ether to afford the unsymmetric double Schiff-base ligand as orange to red powder.

[(3-[(2-[Bis(pyridin-2-ylmethyl)amino]ethylimino)methyl]-2hydroxy-5-methylphenylmethylidene)amino]thiourea $\left(\mathrm{H}_{2}\right.$ tschydra). (2-Aminoethyl)bis(2-pyridylmethyl)amine: $2.79 \mathrm{~g}, 11.5$ mmol; proligand $\mathrm{H}_{2}$ tsc-difo: $2.73 \mathrm{~g}, 11.5 \mathrm{mmol}$. Yield: $4.70 \mathrm{~g}$ (88\%). Anal. calcd for $\mathrm{C}_{24} \mathrm{H}_{27} \mathrm{~N}_{7} \mathrm{OS}(M=461.59)$ : C, 62.4; H, 5.9; $\mathrm{N}, 21.2 ; \mathrm{S}, 6.95 \%$. Found: C, 62.1; H, 5.9; N, 21.1; S, 6.9\%. ${ }^{1} \mathrm{H}$ NMR (400 MHz, DMSO-d 6 , $\delta$ in ppm, see Fig. S6†): 2.26 (s, 3H, H9), $2.80(\mathrm{t}, J=5.5 \mathrm{~Hz}, 2 \mathrm{H}, \mathrm{H}-12), 3.76(\mathrm{t}, J=5.5 \mathrm{~Hz}, 2 \mathrm{H}, \mathrm{H}-11)$, 3.82 (s, 4H, H-13/H-19), 7.22 (m, 3H, H-6 and $\mathrm{H}-17 / \mathrm{H}-23), 7.46$ (d, $J=8.0 \mathrm{~Hz}, 2 \mathrm{H}, \mathrm{H}-15 / \mathrm{H}-21), 7.65$ (ddd, $J=8.0,8.0,1.6 \mathrm{~Hz}, 2 \mathrm{H}$, $\mathrm{H}-16 / \mathrm{H}-22), 8.02$ (s, 1H, $\mathrm{NH}_{2}$ ), 8.04 (m, 1H, H-4), 8.18 (s, 1H, $\mathrm{NH}_{2}$ ), 8.47 (m, 4H, H-10/H-2 and $\left.\mathrm{H}-18 / \mathrm{H}-24\right), 11.48$ (s, 1H, NH), 14.37 (s, $1 \mathrm{H}, \mathrm{OH}) .{ }^{13} \mathrm{C}\left\{{ }^{1} \mathrm{H}\right\}$ NMR (100 MHz, DMSO-d ${ }_{6}, \delta$ in ppm, see Fig. S6†): 19.9 (C9), 53.8 (C12), 54.4 (C11), 59.6 (C13/C19), 118.0 (C7), 121.9 (C3), 122.1 (C17/C23), 122.5 (C15/C21), 125.9 (C5), 129.7 (C4), 133.7 (C6), 136.4 (C16/C22), 137.8 (C2), 148.7 (C18/C24), 159.1 (C14/C20), 160.5 (C8), 166.5 (C10), 177.7 (C1). MS (Micro-ESI neg., $m / z$, rel. int. in \%): $460\left(100,\left[\mathrm{M}-\mathrm{H}^{-}\right), 293\right.$ (37), 255 (20). FT-IR: see Fig. S7. $\dagger$

[(3-[(2-[Bis(pyridin-2-ylmethyl)amino]ethylimino)methyl]-2hydroxy-5-methylphenylmethylidene)amino]urea ( $\left.\mathrm{H}_{2} \mathrm{sc}-\mathrm{hydra}\right)$. (2-Aminoethyl)bis(2-pyridylmethyl)amine: $1.41 \mathrm{~g}, 5.8 \mathrm{mmol}$; proligand $\mathrm{H}_{2}$ sc-difo: $1.29 \mathrm{~g}, 5.8 \mathrm{mmol}$. Yield: $2.32 \mathrm{~g}$ (86\%). Anal. calcd for $\mathrm{C}_{24} \mathrm{H}_{27} \mathrm{~N}_{7} \mathrm{O}_{2} \cdot 0.5 \mathrm{MeOH}(M=461.54)$ : C, 63.8; H, 6.3; N, 21.2\%. Found: C, 63.5; H, 6.3; N, 21.15\%. ${ }^{1} \mathrm{H}$ NMR $(400 \mathrm{MHz}$, DMSO-d $_{6}, \delta$ in ppm, see Fig. S8 $\dagger$ ): 2.25 (s, 3H, H-9), $2.79(\mathrm{t}, J=$ $5.8 \mathrm{~Hz}, 2 \mathrm{H}, \mathrm{H}-12), 3.74$ (t, $J=5.8 \mathrm{~Hz}, 2 \mathrm{H}, \mathrm{H}-11), 3.81$ (s, $4 \mathrm{H}, \mathrm{H}-13 /$ $\mathrm{H}-19), 6.50$ (s, 2H, NH${ }_{2}$ ), 7.15 (m, 1H, H-6), 7.20 (m, 2H, H-17/H23), 7.44 (d, $J=8.1 \mathrm{~Hz}, 2 \mathrm{H}, \mathrm{H}-15 / \mathrm{H}-21), 7.63$ (ddd, $J=8.1,8.1$, $1.6 \mathrm{~Hz}, 2 \mathrm{H}, \mathrm{H}-16 / \mathrm{H}-22), 7.91$ (m, 1H, H-4), 8.20 (s, 1H, H-2), 8.45 (m, 3H, H-10 and $\mathrm{H}-18 / \mathrm{H}-24), 10.28$ (s, 1H, NH), 14.17 (s, 1H, $\mathrm{OH}) .{ }^{13} \mathrm{C}\left\{{ }^{1} \mathrm{H}\right\}$ NMR (100 MHz, DMSO-d 6 , $\delta$ in ppm, see Fig. S8 $\dagger$ ): 20.0 (C9), 53.9 (C12), 54.9 (C11), 59.6 (C13/C19), 118.2 (C7), 122.1 (C17/C23), 122.3 (C3), 123.0 (C15/C21), 126.2 (C5), 128.9 (C4), 132.7 (C6), 134.6 (C2), 136.4 (C16/C22), 148.7 (C18/C24),
156.8 (C1), 158.8 (C8), 159.1 (C14/C20), 166.5 (C10). MS (Micro-ESI pos., $m / z$, rel. int. in \%): $468\left(100,[\mathrm{M}+\mathrm{Na}]^{+}\right)$. FT-IR: see Fig. S9. $\dagger$

[(2-Hydroxy-3-[(pyridin-2ylmethyl)imino]methylphenyl)methylidene]aminothiourea ( $\mathbf{H}_{2}$ tsc-ampy). 2-(Aminomethyl)-pyridine: $456 \mathrm{mg}, 4.21 \mathrm{mmol}$; proligand $\mathrm{H}_{2}$ tsc-difo: $1.00 \mathrm{~g}$, $4.21 \mathrm{mmol}$. Yield: $1.190 \mathrm{~g}(86 \%)$. Anal. calcd for $\mathrm{C}_{16} \mathrm{H}_{17} \mathrm{~N}_{5} \mathrm{OS}(M=327.40)$ : C, 58.7; H, 5.2; N, 21.4; S, 9.8\%. Found: C, 58.4; H, 5.2; N, 21.1; S, 9.5\%. ${ }^{1} \mathrm{H}$ NMR (400 MHz, DMSO-d 6 , $\delta$ in ppm, for see Fig. S10 $\dagger$ ): 2.26 (s, 3H, H-9), 4.91 (s, 2H, H-11), 7.31 (m, 2H, H-6/H-15), 7.41 (d, $J=7.9 \mathrm{~Hz}, 1 \mathrm{H}, \mathrm{H}-13), 7.81(\mathrm{~m}, 1 \mathrm{H}, \mathrm{H}-14), 7.99\left(\mathrm{~s}, 1 \mathrm{H}, \mathrm{NH}_{2}\right)$, 8.04 (m, 1H, H-4), 8.17 (s, 1H, NH ${ }_{2}$ ), 8.39 (s, 1H, H-2), 8.55 (m, 1H, H-16), 8.69 (s, 1H, H-10), 11.46 (s, 1H, NH), 14.18 (s, 1H, $\mathrm{OH}) .{ }^{13} \mathrm{C}\left\{{ }^{1} \mathrm{H}\right\}$ NMR (100 MHz, DMSO-d $6, \delta$ in ppm, see Fig. S10†): 19.9 (C9), 63.0 (C11), 118.5 (C7), 121.5 (C3), 122.2 (C13), 122.6 (C15), 126.9 (C5), 129.4 (C4), 133.9 (C6), 137.1 (C14), 137.3 (C2), 149.3 (C16), 157.5 (C12), 158.6 (C8), 167.5 (C10), 177.8 (C1). MS (Micro-ESI pos., $m / z$, rel. int. in \%): 350 (100, [M + $\left.\mathrm{Na}]^{+}\right)$. FT-IR: see Fig. S11. $\dagger$

[(2-Hydroxy-3-[(pyridin-2ylmethyl)imino]methylphenyl)methylidene]aminourea ( $\mathbf{H}_{2}$ sc-ampy). 2-(Aminomethyl)-pyridine: 586 $\mathrm{mg}, 5.42 \mathrm{mmol}$; proligand $\mathrm{H}_{2} \mathrm{sc}-$ difo: $1.20 \mathrm{~g}, 5.42 \mathrm{mmol}$. Yield: $1.60 \mathrm{~g}$ (95\%). Anal. calcd for $\mathrm{C}_{16} \mathrm{H}_{17} \mathrm{~N}_{5} \mathrm{O}_{2}(M=311.34)$ : C, 61.7; $\mathrm{H}, 5.5$; N, 22.5\%. Found: C, 61.4; H, 5.55; N, 22.7\%. ${ }^{1} \mathrm{H}$ NMR (400 MHz, DMSO-d ${ }_{6}, \delta$ in ppm, see Fig. S12 $\dagger$ ): 2.26 (s, 3H, H-9), 4.90 (s, 2H, H-11), 6.48 (s, 2H, NH N $^{2}, 7.27$ (m, 1H, H-6), 7.31 (m, 1H, H-15), 7.40 (d, J=8.0 Hz, 1H, H-13), 7.85 (m, 1H, H-14), 7.92 (m, 1H, H-4), 8.17 (s, 1H, H-2), 8.55 (m, 1H, H-16), 8.69 (s, 1H, H10), 10.62 (s, 1H, NH), $14.02(\mathrm{~s}, 1 \mathrm{H}, \mathrm{OH}) .{ }^{13} \mathrm{C}\left\{{ }^{1} \mathrm{H}\right\}$ NMR (150 MHz, DMSO-d ${ }_{6}, \delta$ in ppm, see Fig. S12 $\dagger$ ): 19.9 (C9), 63.2 (C11), 118.5 (C7), 121.0 (C3), 122.1 (C13), 122.6 (C15), 127.0 (C5), 129.0 (C4), 132.9 (C6), 134.2 (C2), 137.1 (C14), 149.3 (C16), 156.8 (C1), 157.4 (C12), 157.6 (C8), 167.5 (C10). MS (Micro-ESI pos., $\mathrm{m} / z$, rel. int. in \%): $334\left(100,[\mathrm{M}+\mathrm{Na}]^{+}\right)$. FT-IR: see Fig. S13. $\dagger$

[(2-Hydroxy-3-[N-(2-hydroxyphenyl)carboximidoyl]-5-methylphenylmethylidene)amino]thiourea ( $\mathrm{H}_{3}$ tsc-amph). 2-Aminophenol: $460 \mathrm{mg}, 4.21 \mathrm{mmol}$; proligand $\mathrm{H}_{2}$ tsc-difo: $1.00 \mathrm{~g}, 4.21$ mmol. Yield: $1.118 \mathrm{~g}$ (81\%). Anal. calcd for $\mathrm{C}_{16} \mathrm{H}_{16} \mathrm{~N}_{4} \mathrm{O}_{2}$ $\mathrm{S} \cdot 0.5 \mathrm{MeOH}(M=344.41)$ : C, 57.5; H, 5.3; N, 16.3; S, 9.3\%. Found: C, 57.35; H, 5.0; N, 16.6; S, 9.6\%. ${ }^{1} \mathrm{H}$ NMR $(400 \mathrm{MHz}$, DMSO-d $_{6}, \delta$ in ppm, for see Fig. S14 $\dagger$ ): 2.29 (s, 3H, H-9), 6.88 (dd, $J=8.2 \mathrm{~Hz}, 1 \mathrm{H}, \mathrm{H}-13), 6.97$ (d, $J=8.2 \mathrm{~Hz}, 1 \mathrm{H}, \mathrm{H}-15), 7.13$ (dd, $J=$ $8.2 \mathrm{~Hz}, 1 \mathrm{H}, \mathrm{H}-14), 7.39$ (d, $J=8.2 \mathrm{~Hz}, 1 \mathrm{H}, \mathrm{H}-12), 7.42(\mathrm{~m}, 1 \mathrm{H}, \mathrm{H}-$ 6), $8.00\left(\mathrm{~s}, 1 \mathrm{H}, \mathrm{NH}_{2}\right), 8.08(\mathrm{~m}, 1 \mathrm{H}, \mathrm{H}-4), 8.17\left(\mathrm{~s}, 1 \mathrm{H}, \mathrm{NH}_{2}\right), 8.46(\mathrm{~s}$, $1 \mathrm{H}, \mathrm{H}-2), 8.95$ (s, 1H, H-10), 9.85 (s, 1H, O2H), 11.48 (s, 1H, NH), 14.62 (s, 1H, O1H). ${ }^{13} \mathrm{C}\left\{{ }^{1} \mathrm{H}\right\}$ NMR $\left(100 \mathrm{MHz}, \mathrm{DMSO}_{6}, \delta\right.$ in ppm, see Fig. S14†): 20.0 (C9), 117.0 (C15), 119.3 (C7), 119.5 (C12), 119.7 (C13), 121.6 (C3), 127.1 (C5), 128.4 (C14), 129.8 (C4), 134.0 (C11), 134.3 (C6), 137.4 (C2), 151.2 (C16), 158.6 (C8), 161.3 (C10), 177.8 (C1). MS (Micro-ESI pos., $m / z$, rel. int. in \%): 351 (100, [M + $\left.\mathrm{Na}]^{+}\right)$. FT-IR: see Fig. S15. $\dagger$

[(2-Hydroxy-3-[N-(2-hydroxyphenyl)carboximidoyl]-5-methylphenylmethylidene)amino]urea ( $\mathbf{H}_{3} \mathbf{S c}$-amph). 2-Aminophenol: $74 \mathrm{mg}, 0.68 \mathrm{mmol}$; proligand $\mathrm{H}_{2} \mathrm{sc}$-difo: $150 \mathrm{mg}, 0.68 \mathrm{mmol}$. Yield: $200 \mathrm{~g}$ (91\%). Anal. calcd for $\mathrm{C}_{16} \mathrm{H}_{16} \mathrm{~N}_{4} \mathrm{O}_{3} \cdot 0.5 \mathrm{MeOH}(M=$ 328.35): C, 60.4; H, 5.5; N, 17.1\%. Found: C, 60.5; H, 5.4; N, 17.1\%. ${ }^{1} \mathrm{H}$ NMR (600 MHz, DMSO-d ${ }_{6}, \delta$ in ppm, see Fig. S16 $)$ ): 
2.29 (s, 3H, H-9), 6.50 (s, 2H, $\mathrm{NH}_{2}$ ), 6.88 (dd, $J=8.2 \mathrm{~Hz}, 1 \mathrm{H}, \mathrm{H}-$ 13), 6.98 (d, $J=8.2 \mathrm{~Hz}, 1 \mathrm{H}, \mathrm{H}-15), 7.13$ (dd, $J=8.2 \mathrm{~Hz}, 1 \mathrm{H}, \mathrm{H}-14)$, 7.37 (m, 1H, H-12), 7.38 (m, 1H, H-6), 7.96 (m, 1H, H-4), 8.25 (s, $1 \mathrm{H}, \mathrm{H}-2), 8.93$ (s, 1H, H-10), 9.84 (s, 1H, O2H), 10.29 (s, 1H, NH), 14.48 (s, 1H, O1H). ${ }^{13} \mathrm{C}\left\{{ }^{1} \mathrm{H}\right\}$ NMR $\left(150 \mathrm{MHz}, \mathrm{DMSO}-\mathrm{d}_{6}, \delta\right.$ in ppm, see Fig. S16†): 20.0 (C9), 116.6 (C15), 119.3 (C7), 119.5 (C12), 119.6 (C13), 122.1 (C3), 127.1 (C5), 128.3 (C14), 129.3 (C4), 133.4 (C6), 134.2 (C11), 134.4 (C2), 151.2 (C16), 156.8 (C1), 157.6 (C8), 161.4 (C10). MS (Micro-ESI pos., $m / z$, rel. int. in \%): 335 (100, [M $\left.+\mathrm{Na}]^{+}\right)$. FT-IR: see Fig. S17. $\dagger$

\section{Synthesis of complexes}

[Ni(tsc-difo)PPh $\mathbf{P h}_{3}$. Triphenylphosphane (113 mg, $\left.0.43 \mathrm{mmol}\right)$ and the proligand $\mathrm{H}_{2}$ tsc-difo $(100 \mathrm{mg}, 0.42 \mathrm{mmol}$ ) were suspended in methanol $(5 \mathrm{~mL})$. Triethylamine ( $86 \mathrm{mg}, 0.85 \mathrm{mmol})$ was added to this slurry. This led to a color change from yellow to orange. Subsequently a solution of nickel(II) perchlorate hexahydrate (154.3 $\mathrm{mg}, 0.42 \mathrm{mmol})$ in methanol $(5 \mathrm{~mL})$ was added dropwise to the orange reaction mixture under stirring. The mixture was continuously stirred until a clear red solution was formed. The final reaction solution was filtered and the resulting filtrate was allowed to stand at room temperature. After one day reddish crystals of [Ni(tsc-difo) $\mathrm{PPh}_{3}$ ] precipitated and were collected by filtration. The crystalline material was dried in vacuo for $20 \mathrm{~h}$. Yield: $130 \mathrm{mg}$ (53\%). Anal. calcd for $\mathrm{C}_{28} \mathrm{H}_{24} \mathrm{~N}_{3} \mathrm{NiO}_{2} \mathrm{PS} \cdot 0.7 \mathrm{MeOH}(M=578.67)$ : C, 59.6; H, 4.7; N, 7.3; S, 5.5\%. Found: C, 59.5; H, 4.6; N, 7.2; S, 5.4\%. ${ }^{1} \mathrm{H}$ NMR (400 $\mathrm{MHz}, \mathrm{CD}_{2} \mathrm{Cl}_{2}, \delta$ in ppm, see Fig. S18†): 2.23 (s, 3H, H-9), 4.79 (s, $2 \mathrm{H}, \mathrm{NH}_{2}$ ), 7.33 (d, $\left.{ }^{4} J=2.4 \mathrm{~Hz}, 1 \mathrm{H}, \mathrm{H}-4\right), 7.43(\mathrm{~m}, 7 \mathrm{H}, \mathrm{H}-6$ and $\left.\mathrm{PPh}_{3}\right), 7.52\left(\mathrm{~m}, 3 \mathrm{H}, \mathrm{PPh}_{3}\right), 7.80\left(\mathrm{~m}, 6 \mathrm{H}, \mathrm{PPh}_{3}\right), 8.21\left(\mathrm{~d},{ }^{4} J_{\mathrm{PH}}=8.9\right.$ $\mathrm{Hz}, 1 \mathrm{H}, \mathrm{H}-2), 8.90$ (s, 1H, H-10). ${ }^{13} \mathrm{C}\left\{{ }^{1} \mathrm{H}\right\} \mathrm{NMR}\left(100 \mathrm{MHz}, \mathrm{CD}_{2} \mathrm{Cl}_{2}\right.$, $\delta$ in ppm, see Fig. S18†): 20.1 (C9), 121.3 (C7), 124.6 (C5), 126.2 (C3), $129.0\left(\mathrm{~d},{ }^{3} J_{\mathrm{PC}}=10.3 \mathrm{~Hz}\right), 129.4\left(\mathrm{~d},{ }^{1} J_{\mathrm{PC}}=46.9 \mathrm{~Hz}\right), 131.5(\mathrm{~d}$, $\left.{ }^{4} J_{\mathrm{PC}}=2.1 \mathrm{~Hz}\right), 132.1(\mathrm{C} 6), 134.7\left(\mathrm{~d},{ }^{2} J_{\mathrm{PC}}=10.5 \mathrm{~Hz}\right), 139.7(\mathrm{C} 4)$, 151.7 (C2), 161.6 (C8), 172.3 (d, ${ }^{3} J_{\mathrm{PC}}=16.8 \mathrm{~Hz}, \mathrm{C} 1$ ), 191.2 (C10). ${ }^{31} \mathrm{P}\left\{{ }^{1} \mathrm{H}\right\}$ NMR (162 MHz, $\mathrm{CD}_{2} \mathrm{Cl}_{2}, \delta$ in $\left.\mathrm{ppm}\right):$ 20.63. UV/Vis $\left(\mathrm{CH}_{2} \mathrm{Cl}_{2}, \lambda_{\max }\right.$ in $\mathrm{nm}, \varepsilon$ in $\mathrm{M}^{-1} \mathrm{~cm}^{-1}$, see Fig. S19†): 571 (112, shoulder), 445 (10 155), 427 (8770, shoulder), 386 (10 349), 370 (8458, shoulder), 340 (5907), 303 (18 189). MS (Micro-ESI pos., $\mathrm{m} / z$, rel. int. in \%): $577.8\left(66,[\mathrm{M}+\mathrm{Na}]^{+}\right), 413$ (26), 333 (58), 301 (100), 263 (62, P(Ph)3). FT-IR: see Fig. S20.†

[ $\mathbf{Z n}_{2}$ (tsc-hydra)(OAc) $)_{2}$. To a suspension of $\mathrm{H}_{2}$ tsc-hydra (241 $\mathrm{mg}, 0.52 \mathrm{mmol})$ in acetonitrile $(10 \mathrm{~mL})$ was added a solution of triethylamine $(107 \mathrm{mg}, 1.06 \mathrm{mmol})$ in acetonitrile $(2 \mathrm{~mL})$. Subsequently a solution of zinc(II) acetate dihydrate $(228 \mathrm{mg}$, $1.04 \mathrm{mmol})$ in acetonitrile/methanol $(5 \mathrm{~mL} / 5 \mathrm{~mL})$ was added dropwise to the reaction mixture. A clear orange solution was formed. Slow evaporation of the solvent in air gave yellow crystals which were dried in air. Yield: $100 \mathrm{mg}$ (25\%). Anal. calcd for $\mathrm{C}_{28} \mathrm{H}_{31} \mathrm{~N}_{7} \mathrm{O}_{5} \mathrm{SZn}_{2} \cdot 2 \mathrm{H}_{2} \mathrm{O}(M=744.45)$ : C, 45.2; $\mathrm{H}, 4.7 ; \mathrm{N}, 13.2$; S, 4.3\%. Found: C, 44.9; H, 4.4; N, 13.2; S, 4.2\%. ${ }^{1} \mathrm{H}$ NMR (400 MHz, DMSO-d ${ }_{6}, \delta$ in ppm, see Fig. S21†): 1.65 (s, 6H, OAc ${ }^{-}$), 2.19 (s, 3H, H-9), 2.82 (s(br), 2H, H-12), 2.98 (m, 2H, H-11), 4.34 (d, J $\left.=15.7 \mathrm{~Hz}, 2 \mathrm{H}, \mathrm{H}_{\mathrm{a}}-13 / \mathrm{H}_{\mathrm{a}} 19\right), 4.62\left(\mathrm{~d}, J=15.7 \mathrm{~Hz}, 2 \mathrm{H}, \mathrm{H}_{\mathrm{b}}-13 /\right.$ $\left.\mathrm{H}_{\mathrm{b}} 19\right), 6.22$ (s, 2H, $\mathrm{NH}_{2}$ ), $7.02(\mathrm{~m}, 1 \mathrm{H}, \mathrm{H}-6), 7.30$ (m, 1H, H-4), 7.43 (m, 2H, H-17/H-23), 7.51 (d, $J=8.0 \mathrm{~Hz}, 2 \mathrm{H}, \mathrm{H}-15 / \mathrm{H}-21$ ),
7.96 (dd, $J=80 \mathrm{~Hz}, 2 \mathrm{H}, \mathrm{H}-16 / \mathrm{H}-22), 8.10$ (s, 1H, H-2), 8.40 (s, 1H, H-10), 8.53 (s(br), 2H, H-18/H-24). ${ }^{13} \mathrm{C}\left\{{ }^{1} \mathrm{H}\right\}$ NMR $(150 \mathrm{MHz}$, DMSO-d $_{6}, \delta$ in ppm, see Fig. S21†): 19.2 (C9), 24.0 (C26/C28), 54.3 (C11), 57.4 (C12), 60.5 (C13/C19), 120.7 (C7), 123.2 (C5), 123.5 (C3/C15/C21), 124.0 (C17/C23), 137.9 (C6), 138.8 (C4), 139.4 (C16/C22), 147.6 (C18/C24), 151.0 (C2), 155.5 (C14/C20), 165.4 (C8), 168.0 (C10), 174.1 (C25/C27), 174.1 (C1). MS (Micro-ESI pos., $m / z$, rel. int. in \%, see Fig. S22 $\dagger$ ): 648 (100, [M $\left.\mathrm{OAc}]^{+}\right), 608\left(67,[\mathrm{M}-2 \mathrm{OAc}+\mathrm{OH}]^{+}\right), 588(57), 490(22), 448$ (41). FT-IR: see Fig. S23.†

\section{X-ray crystallographic studies}

The intensity data were collected on a Nonius KappaCCD diffractometer, using graphite-monochromated Mo-K $\alpha$ radiation $(\lambda=0.71073 \AA$ ). Data were corrected for Lorentz and polarization effects. Absorption was taken into account on a semi-empirical basis using multiple-scans. ${ }^{56-58}$ The structures were solved by direct methods (SHELXS) ${ }^{59}$ and refined by fullmatrix least squares techniques against $F_{\mathrm{o}}{ }^{2}$ (SHELXL-97). ${ }^{59} \mathrm{In}$ the crystal structure of $\left[\mathrm{Zn}_{2}(\right.$ tsc-hydra $\left.)(\mathrm{OAc})_{2}\right] \cdot \mathrm{MeCN} \cdot \mathrm{H}_{2} \mathrm{O}$ one of the pyridyl groups was found to be slightly disordered on two positions (ratio of site occupation factors is about 6 to 1). The hydrogen atoms of the amine group (N1) and the water molecule $(\mathrm{O} 1 \mathrm{~W})$ in the crystal structure of the zinc complex were located by difference Fourier synthesis and refined isotropically. All other hydrogen atom positions were included at calculated positions with fixed thermal parameters. All non-hydrogen and non-disordered atoms were refined using anisotropic thermal parameters. Crystallographic data as well as structure solution and refinement details for $\left[\mathrm{Ni}\right.$ (tsc-difo) $\left.\mathrm{PPh}_{3}\right] \cdot 2 \mathrm{MeOH}$ and $\left[\mathrm{Zn}_{2}\right.$ (tsc-hydra) $\left.(\mathrm{OAc})_{2}\right] \cdot \mathrm{MeCN} \cdot \mathrm{H}_{2} \mathrm{O}$ are summarized in Table S1. $\dagger$

\section{Results and discussion}

\section{Mono Schiff-base proligands}

First attempts to synthesize the desired mono Schiff-base proligand $\mathrm{H}_{2}$ tsc-difo depicted in Fig. 2 utilized the slow addition of a diluted thiosemicarbazide (tsc) solution to a concentrated solution of dfc in methanol over a period of one week. Although this successfully led to the formation of the desired mono Schiff base, the product contained a considerable amount of the symmetric double Schiff base as byproduct. Since the resulting product mixture was only sparingly soluble in acetonitrile and chloroform, standard recrystallization could not be applied.

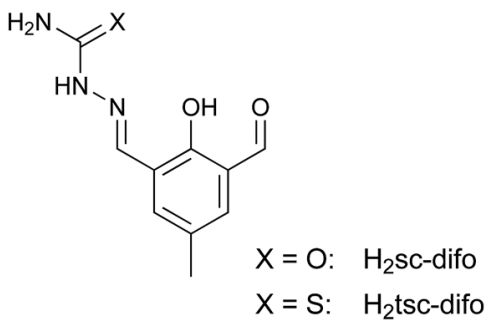

Fig. 2 Mono Schiff-base proligands. 
However, attempts by Soxhlet extraction with chloroform over a period of four days could successfully be utilized to separate the unsymmetric proligand from the undesired symmetric side product. $\mathrm{H}_{2}$ tsc-difo was extracted from the crude reaction product and precipitated in pure form as a yellow solid which is evident by comparison of the NMR spectra before and after extraction (Fig. S24 $\dagger$ ). Based on these observations we supposed that under conditions of continuous dilution over the whole period of reaction, with respect to the amine component tsc, it should be possible to generate solely $\mathrm{H}_{2}$ tsc-difo without any symmetric byproduct.

Along this line it turned out to be beneficial that dfc shows a solubility in acetonitrile which is by far larger than that of tsc. This allows during the reaction to simultaneously maintain a rather high dfc concentration paired with a situation of continuous dilution with respect to tsc. The desired idealized reaction conditions should combine a steady but very small intake of tsc to a highly concentrated dfc reaction solution. These conditions, best described as slow solution transport, can be achieved by a simple reaction setup which utilizes the solvent extraction of tsc from a fritted glass filter by acetonitrile under reflux conditions as depicted in Fig. S1. $\dagger$ To maintain the desired dilution conditions with respect to the amine component throughout the whole reaction time a 1.5 stoichiometric excess of the carbonyl component dfc was used. Within a period of a about two days the complete amount of tsc was eluted into the reaction mixture and the proligand $\mathrm{H}_{2}$ tsc-difo was formed as yellow solid precipitate insoluble in the reaction mixture. As the solubility of the mono Schiff-base proligand increases with temperature, which would favor the formation of the undesired symmetric byproduct, the reaction temperature was kept below approximately $40{ }^{\circ} \mathrm{C}$ by reducing the pressure in the reaction vessel and thereby lowering the boiling point of the reaction solvent acetonitrile. The remaining excess of dfc can easily be recovered from the final solid reaction product by washing the yellow powder several times with either chloroform or dichloromethane. The scale-up of this procedure was optimized to produce the proligand in gram scale and over $90 \%$ yield. The basic limiting factor is the solubility of the dfc starting material in the given reaction volume.

This synthetic strategy should be transferable to the reaction of dfc with semicarbazide (sc). However, the varied solubility properties of semicarbazide and the fact that it is commercially available as hydrochloride, require some modifications of the applied procedure. In this case it was necessary to utilize dichloromethane as reaction solvent, since the solubility of semicarbazide hydrochloride is too high in acetonitrile to prevent the formation of the undesired symmetric side product. Moreover, to generate the free semicarbazide triethylamine was added as base to the reaction mixture. As in the previous case the semicarbazide is slowly eluted into the reaction flask. The product $\mathrm{H}_{2}$ sc-difo (see Fig. 2) is formed as a pale yellow precipitate which can be isolated from the crude reaction mixture by filtration and subsequent washing with dichloromethane. However, the yield is slightly lower compared to the previous case of the thiosemicarbazone derivative as $\mathrm{H}_{2} \mathrm{sc}$-difo possesses a somewhat better solubility and is therefore partially lost during the washing process.

Both proligands $\mathrm{H}_{2}$ sc-difo and $\mathrm{H}_{2}$ tsc-difo can be obtained in high yields as pure solid materials. This synthetic route provides a large scale access to these versatile ligand systems which can be utilized for further derivatization in various ways. The available free carbonyl group of the proligands can be functionalized with other amine components to yield the desired unsymmetric double Schiff bases. Alternatively the proligands can directly used for coordination of metal ions leading to mononuclear complexes which in turn could be further functionalized at the remaining carbonyl group.

\section{Double Schiff bases}

Starting from the proligands $\mathrm{H}_{2}$ sc-difo and $\mathrm{H}_{2}$ tsc-difo unsymmetric double Schiff bases can be derived by condensation in methanol with the appropriate amine components. To probe the synthetic versatility of this approach we utilized three different primary amines including aliphatic and aromatic examples which vary the number and nature of the introduced donor atoms, namely (2-aminoethyl)bis(2-pyridylmethyl)amine, 2 -(aminomethyl)-pyridine and 2-aminophenol. These reactions were performed under heterogeneous conditions since the proligands were only sparingly soluble in methanol. The resulting double Schiff bases depicted in Fig. 3 are obtained in high yield and purity without any indication of imine metathesis during the course of reactions.
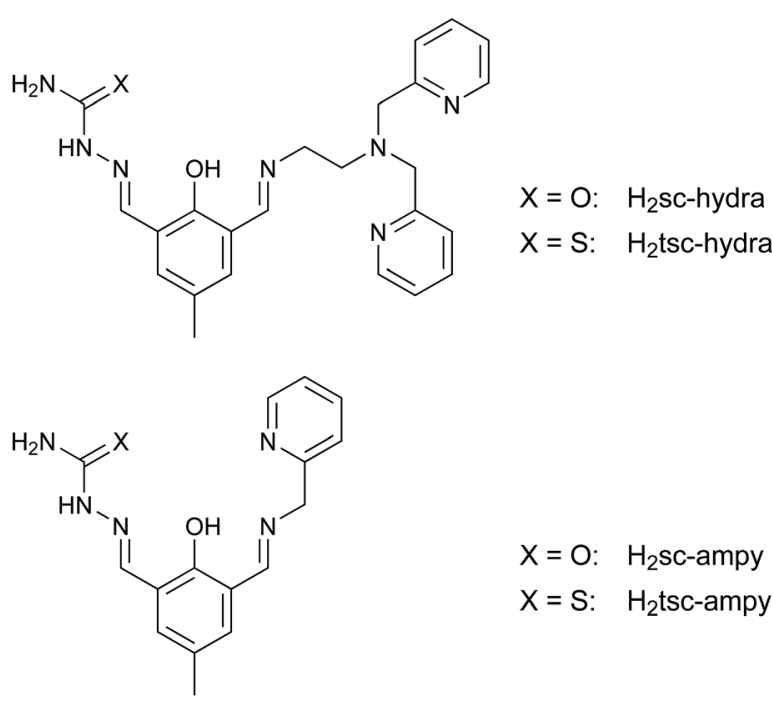

$$
\begin{array}{ll}
X=\mathrm{O}: & \mathrm{H}_{2} \text { sc-ampy } \\
\mathrm{X}=\mathrm{S}: & \mathrm{H}_{2} \text { tsc-ampy }
\end{array}
$$

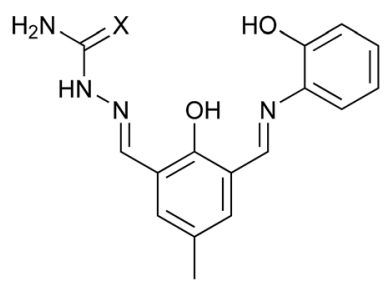

$X=\mathrm{O}: \mathrm{H}_{2}$ sc-amph

Fig. 3 Synthesized double Schiff-base ligands based on the proligands $\mathrm{H}_{2} \mathrm{SC}$-difo and $\mathrm{H}_{2}$ tsc-difo. 
All these potential ligands contain two distinct binding pockets for the coordination of metal ions. According the nature of the second amine group introduced these ligands fall into two groups with either an additional flexible or rigid donor fragment, besides the generally present semicarbazone or thiosemicarbazone moiety which provides a binding pocket with rigid tridentate donor set.

Selected ${ }^{1} \mathrm{H}$ NMR data for the double Schiff bases are summarized in Table 1. The resonances of the methine protons assigned to the imine groups are observed in the usual range and show the expected shielding effect when compared to the corresponding resonance of the proligands (H-10). These data further indicate the presence of strong hydrogen-bonding interaction between the hydroxy group of the bridging aromatic moiety and the adjacent imino group as depicted in Fig. 4. This leads to a resonance-assisted hydrogen bond $\mathrm{N}-\mathrm{H} \cdots \mathrm{O}$ which is well known for Schiff bases containing salicylidene moieties. ${ }^{60,61}$ As a consequence the corresponding proton resonance is considerably shifted downfield to values of more than $14 \mathrm{ppm}$ in comparison to the resonances observed for the proligands $\mathrm{H}_{2}$ sc-difo and $\mathrm{H}_{2}$ tsc-difo at around $11 \mathrm{ppm}$ lacking this interaction. A comparison of selected ${ }^{13} \mathrm{C}$ NMR data for the proligands and double Schiff bases are summarized in Table S2. $\dagger$

The observed NMR data is consistent with a preserved solution behavior for the semicarbazone and thiosemicarbazone moieties within the two series of mono and double Schiff bases. A usually observed structural feature for these class of compounds is the almost planar $\mathrm{C}=\mathrm{N}-\mathrm{NH}-\mathrm{CX}-$ $\mathrm{NH}_{2}$ backbone with a trans arrangement of the azomethine and the $\mathrm{X}(\mathrm{O}, \mathrm{S})$ atom as depicted in Fig. $5 .^{62}$ For the

Table 1 Selected ${ }^{1} \mathrm{H}$ NMR data for mono and double Schiff bases $(\delta /$ ppm)

\begin{tabular}{lllllll}
\hline Ligand & $\mathrm{N}-\mathrm{H} \cdots \mathrm{O}$ & $\mathrm{OH}$ & $\mathrm{H}-10$ & $\mathrm{H}-2$ & $\mathrm{NH}$ & $\mathrm{NH}_{2}$ \\
\hline $\mathrm{H}_{2}$ sc-difo & - & 11.13 & 10.09 & 8.13 & 10.38 & 6.52 \\
$\mathrm{H}_{2}$ tsc-difo & - & 10.91 & 10.03 & 8.35 & 11.51 & 8.08 \\
& & & & & & 8.24 \\
$\mathrm{H}_{2}$ sc-hydra & 14.17 & - & 8.45 & 8.20 & 10.28 & 6.50 \\
$\mathrm{H}_{2}$ tsc-hydra & 14.37 & - & 8.47 & 8.47 & 11.48 & 8.02 \\
& & & & & & 8.18 \\
$\mathrm{H}_{2}$ sc-ampy & 14.02 & - & 8.69 & 8.17 & 10.62 & 6.48 \\
$\mathrm{H}_{2}$ tsc-ampy & 14.18 & - & 8.69 & 8.39 & 11.46 & 7.99 \\
& & & & & & 8.17 \\
$\mathrm{H}_{3}$ sc-amph & 14.48 & 9.84 & 8.93 & 8.25 & 10.29 & 6.50 \\
$\mathrm{H}_{3}$ tsc-amph & 14.62 & 9.85 & 8.95 & 8.46 & 11.48 & 8.00 \\
& & & & & & 8.17
\end{tabular}<smiles></smiles>

Fig. 4 Tautomerization between the hydroxy-imine and keto-amine forms of the free double Schiff-base ligands in solution.

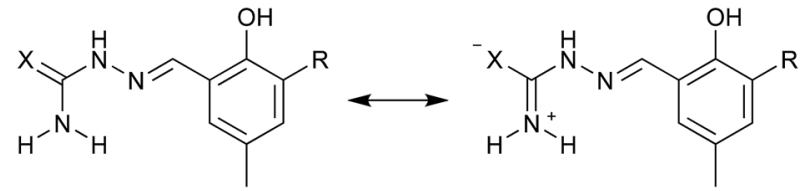

Fig. 5 Mesomeric forms for the thiosemicarbazone based ligands $\mathrm{H}_{2}$ tsc-difo, $\mathrm{H}_{2}$ tsc-hydra, $\mathrm{H}_{2}$ tsc-ampy and $\mathrm{H}_{3}$ tsc-amph preventing free rotation of the $\mathrm{NH}_{2}$ group.

thiosemicarbazones this is known to lead to restricted rotation of the $\mathrm{NH}_{2}$ group, ${ }^{\mathbf{6 3 , 6 4}}$ which might be attributed to an increased contribution of the zwitterionic resonance form (see Fig. 5) as well as the possible hydrogen bonding of one of the $\mathrm{NH}_{2}$ protons with the azomethine nitrogen atom. This is obvious from two independent resonances for the $\mathrm{NH}_{2}$ protons within the thiosemicarbazone series which are both shifted downfield with respect to the corresponding semicarbazones.

For the double Schiff base $\mathrm{H}_{2}$ tsc-hydra this effect has been more closely examined by variable temperature ${ }^{1} \mathrm{H}$ NMR spectroscopy with the resulting spectra depicted in Fig. 6. The two resonances observed for the $\mathrm{NH}_{2}$ group at room temperature coalesce upon increasing the temperature. From the spectral data the free energy of activation $\Delta G^{\star}$ can be estimated ${ }^{65}$ to 69.9 $\mathrm{kJ} \mathrm{mol}^{-1}$ which is in good agreement with reported values. ${ }^{66}$

\section{$\mathrm{Ni}$ (II) complex with the proligand $\mathrm{H}_{2}$ tsc-difo}

The mononuclear complex [Ni(tsc-difo) $\mathrm{PPh}_{3}$ ] was synthesized by slow addition of a methanol solution of nickel(II) perchlorate hexahydrate to a slurry of the mono Schiff-base proligand $\mathrm{H}_{2}$ tscdifo containing one equivalent of triphenylphosphane as potential coligand and two equivalents of triethylamine as base. Upon complexation of the nickel ions a color change from yellow to dark red is observed and the reaction mixture turns in a clear red solution. The observed color indicates a squareplanar coordination geometry at the nickel(II) ion, as expected for a coordination of the strong phosphane ligand. This is

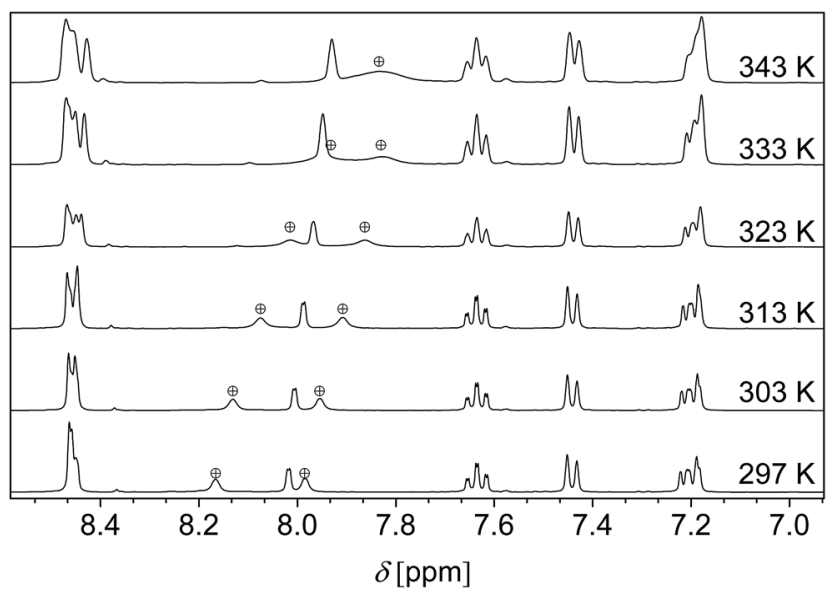

Fig. 6 Variable temperature ${ }^{1} \mathrm{H}$ NMR spectra for $\mathrm{H}_{2}$ tsc-hydra measured at a spectrometer frequency of $400 \mathrm{MHz}$ showing the coalescence for the proton resonances of the $\mathrm{NH}_{2}$ group (marked peaks). 
confirmed by the UV/Vis spectrum of the isolated crystalline complex which is typical for a square-planar nickel(II) complex ${ }^{67}$ with thiosemicarbazone ligand featuring additional chargetransfer bands. . $^{6,68-70}$

The well resolved ${ }^{1} \mathrm{H}$ NMR spectrum of [Ni(tsc-difo) $\mathrm{PPh}_{3}$ ] measured for a dichloromethane- $\mathrm{d}_{2}$ solution is consistent with the expected diamagnetic ground state for a square-planar configuration at the nickel(II) center. The protons related to the resonance observed at $4.79 \mathrm{ppm}$ are affected by $\mathrm{H}-\mathrm{D}$ exchange and consequently assigned as the $\mathrm{NH}_{2}$ group of the thiosemicarbazone moiety, which is well within the usually observed range for anionic thiosemicarbazones coordinated to metal ions. ${ }^{50}$ The fact that in contrast to the free ligand only one resonance is observed for the $\mathrm{NH}_{2}$ group can be attributed to missing intramolecular hydrogen bonding due to an altered configuration of the thiosemicarbazone moiety in the complex. The protons related to the second resonance showing $\mathrm{H}-\mathrm{D}$ exchange characteristic observed at $3.42 \mathrm{ppm}$ are assigned to methanol molecules which are included in the crystal structure. Based on the integration of the resonance peak this corresponds to a methanol content of about 0.7 equivalents per complex unit which is in good agreement with the elemental analysis of the crystalline material dried in vacuo. The resonance of the triphenylphosphane protons are observed in the usual range, ${ }^{50}$ with the multiplet at $7.43 \mathrm{ppm}$ being superimposed with the resonance of the ring proton $\mathrm{H}-6$ of the 2,6diformylcresol moiety. The resonance of the azomethine proton $(\mathrm{H}-2)$ is slightly shifted upfield upon coordination to $8.21 \mathrm{ppm}$ and is split to a doublet due to coupling with the phosphorus atom of the triphenylphosphane in trans position at the nickel ion with a rather large coupling constant ${ }^{4} J_{\mathrm{PH}}=8.9 \mathrm{~Hz} .{ }^{71} \mathrm{The}$ observation of a rather large ${ }^{4} J_{\mathrm{PH}}$ coupling indicates the presence of a highly rigid structural arrangement of the involved bonding backbone in solution. ${ }^{72}$ The ${ }^{31} \mathrm{P}$ NMR resonance for [Ni(tsc-difo) $\mathrm{PPh}_{3}$ ] observed at $20.63 \mathrm{ppm}$ is consistent with the usual range for coordination shifts observed for triphenylphosphane coordinated to nickel(II) ions. ${ }^{73}$

Crystals of [Ni(tsc-difo) $\mathrm{PPh}_{3}$ ] were obtained by slow evaporation of the solvent from the filtrated reaction mixture and were found to crystallize in the monoclinic space group $P 2_{1} / n$ together with two molecules of methanol. The molecular structure of the neutral complex is depicted in Fig. 7 (selected bond angle see Table S3 $\dagger$ ) and confirms the square-planar geometry at the nickel(II) center. The almost ideal square-planar coordination environment is given by the donor atoms $\mathrm{O} 1, \mathrm{~N} 3$ and $\mathrm{S}$ of the proligand and $\mathrm{P}$ of the triphenylphosphane with a deviation of the nickel atom from the mean plane by only $2 \mathrm{pm}$. The bond lengths at the nickel(II) ion are within the expected range for similar complexes and consistent with the deprotonated thiolate form of the thiosemicarbazone fragment expected for a neutral complex. ${ }^{64,70,71}$ The bite angles for the five- and six-membered chelate rings of the tridentate thiosemicarbazone ligand are 95.1 (O1-Ni-N3) and 87.3 (N3-Ni-S1), respectively. The two planar chelate rings show a dihedral angle of $12^{\circ}$, which is due to a slight rotation about the $\mathrm{C} 2-\mathrm{C} 3$ bond.

The two additional molecules of methanol in the crystal structure are involved in hydrogen bonding between the $\mathrm{NH}_{2}$

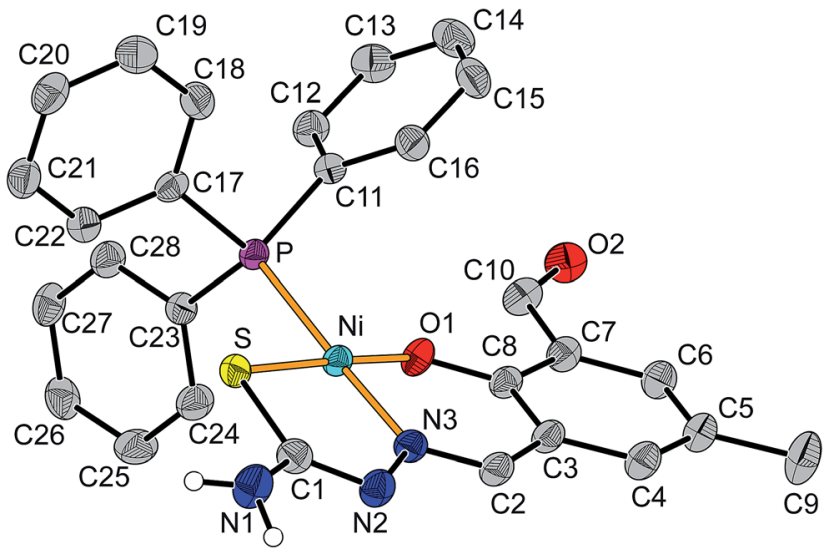

Fig. 7 Molecular structure of [Ni(tsc-difo)PPh 3 ]. Thermal ellipsoids are drawn with $50 \%$ probability level and hydrogen atoms attached to carbon are omitted for clarity. Pertinent distances (in pm): $\mathrm{Ni}-\mathrm{S}$ 212.82(8), Ni-P 219.68(8), Ni-O1 185.8(2), Ni-N3 188.7(2), S-C1 175.2(3), N1-C1 135.6(4), N2-C1 130.5(4), N2-N3 139.9(3), N3-C2 130.3(4).

group (N1) and the aldehyde moiety (O2) of a neighboring complex molecule leading to the formation of a chain along the crystallographic [101] direction as depicted in Fig. 8. In addition $\mathrm{NH} / \pi$ interactions are observed between the second proton of the $\mathrm{NH}_{2}$ groups of the thiosemicarbazone moiety and the aromatic ring of an adjacent complex. ${ }^{74,75}$ This leads to a zig-zag chain like association along the [010] direction (see Fig. S25†).

\section{Dinuclear Zn(II) complex with $\mathbf{H}_{2}$ tsc-hydra}

The complex $\left[\mathrm{Zn}_{2}(\mathrm{tsc}-\mathrm{hydra})(\mathrm{OAc})_{2}\right]$ was obtained from the reaction of two equivalents of zinc(II) acetate dihydrate and the double Schiff-base ligand $\mathrm{H}_{2}$ tsc-hydra in a mixture of acetonitrile and methanol in the presence of triethylamine as base. The constitution of the complex was confirmed by analytical and spectroscopic methods. In particular the solution structure was studied by NMR spectroscopy.

The ${ }^{1} \mathrm{H}$ NMR spectra indicate significant changes upon coordination of the $\mathrm{H}_{2}$ tsc-hydra to the zinc(II) ions with the observed resonances being generally broader than in the case of the free ligand. As in the case of the $\left[\mathrm{Ni}(\mathrm{tsc}-\mathrm{difo}) \mathrm{PPh}_{3}\right]$ the thiosemicarbazone moiety shows the typical features expected for the coordinated thiolate form with a singlet at $6.22 \mathrm{ppm}$ for the protons of the $\mathrm{NH}_{2}$ group. The latter assignment was confirmed

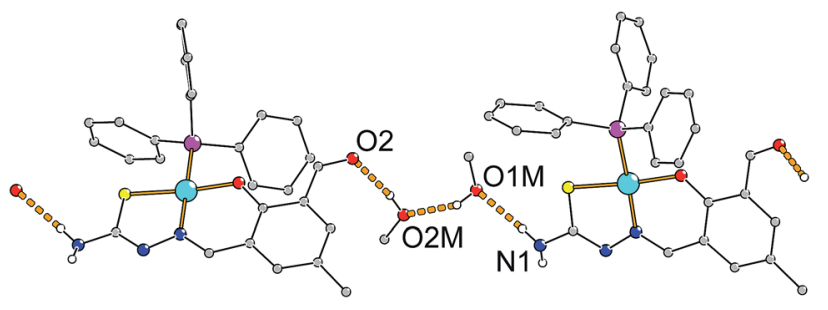

Fig. 8 Hydrogen bonded chains in the crystal structure of [Ni(tsc-difo) $\left.\mathrm{PPh}_{3}\right] \cdot 2 \mathrm{MeOH}$ along the [101] direction. Pertinent distances (in pm):

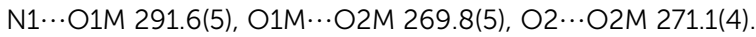


by $\mathrm{H}-\mathrm{D}$ exchange experiments. The two pyridyl rings give rise to only one set of resonances consistent with the equivalence of the two coordinated pyridyl moieties. Similarly for the two acetate anions present in the complex only a single broad resonance at $1.65 \mathrm{ppm}$ is observed indicating their chemical equivalence on the NMR time scale. The resonances for the methylene protons within the ethylenediamine bridge observed at 2.82 (C12) and 2.98 ppm (C11) show the basic trends upon coordination usually observed in the literature. ${ }^{48,76,77}$ However, in contrast to the free ligand and to an earlier reported dinuclear zinc complex with a similar ligand framework spin-spin coupling is not resolved. ${ }^{48}$ Moreover, the resonance for the methylene group (2.82 $\mathrm{ppm}$ ) attached to the tertiary nitrogen donor appears as a very broad singlet with a width at half-height of about $125 \mathrm{~Hz}$. On the other hand, for the methylene hydrogens of the pyridyl arms (C13 and $\mathrm{C} 19$ ) a well resolved $\mathrm{AB}$ pattern with a coupling constant of $16.8 \mathrm{~Hz}$ is observed. ${ }^{65}$ This is typical for a geminal coupling related to this type of coordination pocket and clearly indicates the stereochemical disparity of the involved hydrogen atoms. ${ }^{48,78}$

Crystals of $\left.\left[\mathrm{Zn}_{2} \text { (tsc-hydra)(OAc) }\right)_{2}\right]$ suitable for single crystal analysis were obtained by slow evaporation of the solvent. The neutral complex was found to co-crystallize with one additional molecule of water and acetonitrile as $\left[\mathrm{Zn}_{2}(\mathrm{tsc}-\mathrm{hydra})(\mathrm{OAc})_{2}\right]$. $\mathrm{MeCN} \cdot \mathrm{H}_{2} \mathrm{O}$ in the monoclinic space group $P 2_{1} / n$. The molecular structure of the neutral complex is depicted in Fig. 9 (selected bond angle see Table $\mathrm{S} 4 \dagger$ ).

Two different binding modes are observed for the two coordinated zinc(II) ions. Zn1 is found in a five-coordinate square-pyramidal environment with an $\left[\mathrm{NO}_{3} \mathrm{~S}\right]$ donor set whereas for $\mathrm{Zn} 2$ a six-coordinate octahedral geometry with $\left[\mathrm{N}_{4} \mathrm{O}_{2}\right]$ donor set is observed. This is not surprising, as zinc(II) ions usually show no specific structural preferences. Therefore

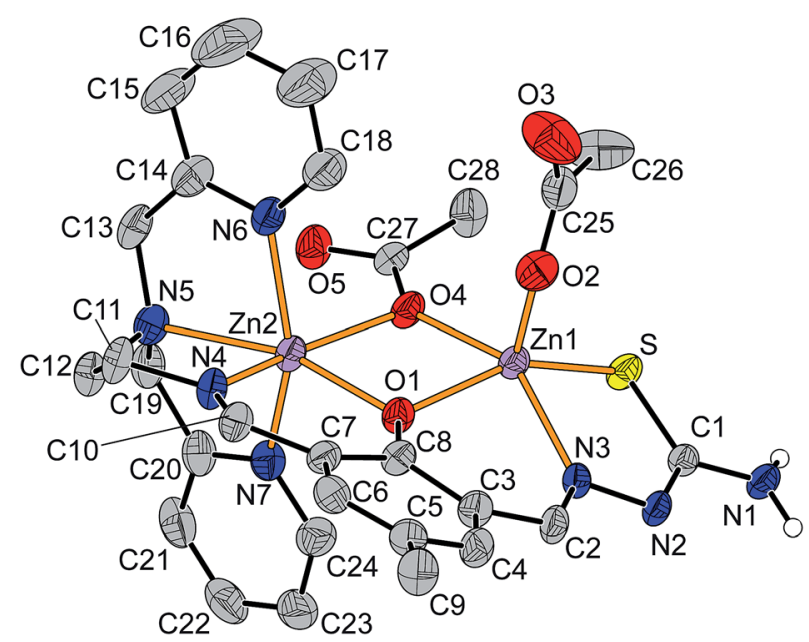

Fig. 9 Molecular structure of $\left[\mathrm{Zn}_{2}(\mathrm{tsc}-\mathrm{hydra})(\mathrm{OAc})_{2}\right]$. Thermal ellipsoids are drawn with $50 \%$ probability level and hydrogen atoms attached to carbon are omitted for clarity. Pertinent distances (in pm): Zn1-S 235.11(12), Zn1-O1 212.3(3), Zn1-O2 197.6(3), Zn1-O4 206.8(3), Zn1-N3 209.9(3), Zn2-O1 212.4(3), Zn2-O4 210.5(3), Zn2N4 209.6(4), Zn2-N5 227.7(3), Zn2-N6 214.0(4), Zn2-N7 210.6(4). the overall structure can be expected as being governed by the donor properties and the flexibility of the two distinctly different binding pockets ligand system. The overall coordination of the zinc(II) ions is complemented by two additional acetate anions one in a $\mu, \eta^{1}$-bridging mode and the second one as a terminal monodentate ligand at zinc center located in the thiosemicarbazone pocket ( $\mathrm{Zn} 1)$.

The central $\mathrm{Zn}_{2} \mathrm{O}_{2}$ moiety is virtually planar within a deviation of less than $2 \mathrm{pm}$ from the mean plane. The two corresponding basal coordination planes at the square-planar Zn1 center (S, O1, O4, and N3) and the octahedral Zn2 center $(\mathrm{O} 1$, $\mathrm{O} 4, \mathrm{~N} 4$, and N5) show dihedral angles of $18^{\circ}$ and $7^{\circ}$ with the central $\mathrm{Zn}_{2} \mathrm{O}_{2}$ moiety, respectively. Interestingly the deviations of the zinc ions from the respective mean planes exhibit distinct differences (Zn1: $58 \mathrm{pm}$; Zn2: $3 \mathrm{pm}$ ) indicating considerable distortion within the basal coordination plane at the $\mathrm{Zn} 2$ center. This also reflects in the deviation of the nitrogen donor atoms N4 (-59 pm) and N5 (21 pm) from the mean plane of the central $\mathrm{Zn}_{2} \mathrm{O}_{2}$ moiety. The overall situation is depicted in Fig. 10.

To accommodate the rigidity of the $\pi$ conjugated part of the ligand backbone to the described distortion the bridging phenolate fragment is tilted with respect to the central $\mathrm{Zn}_{2} \mathrm{O}_{2}$ moiety. This corresponds to a rotation about the $\mathrm{C} 2-\mathrm{C} 3$ bond leading to a dihedral angle of around $16^{\circ}$ (see Fig. S26 $\dagger$ ). Moreover, there is an additional source of distortion for the pyridyl based binding compartment of the ligand system around $\mathrm{Zn} 2$ which is due to the five-membered chelate rings leading to significant decrease of the trans angles with respect to an ideal octahedral geometry (O1-Zn2-N5 $161.9^{\circ}, \mathrm{O} 4-\mathrm{Zn} 2-$ $\mathrm{N} 4155.6^{\circ}, \mathrm{N} 6-\mathrm{Zn} 2-\mathrm{N} 71^{149.3^{\circ}}$ ). As a consequence there is enough space opposite to the ligand backbone at the two zinc(II) ions to allow a coplanar orientation of the bridging acetate anion with respect to the central $\mathrm{Zn}_{2} \mathrm{O}_{2}$ moiety.

The supramolecular arrangement within the crystal structure is governed by hydrogen bonding between pairs of neutral complexes via the thiosemicarbazone fragment of adjacent molecules. Together with hydrogen bonding towards the additional co-crystallized water molecule this leads to the formation

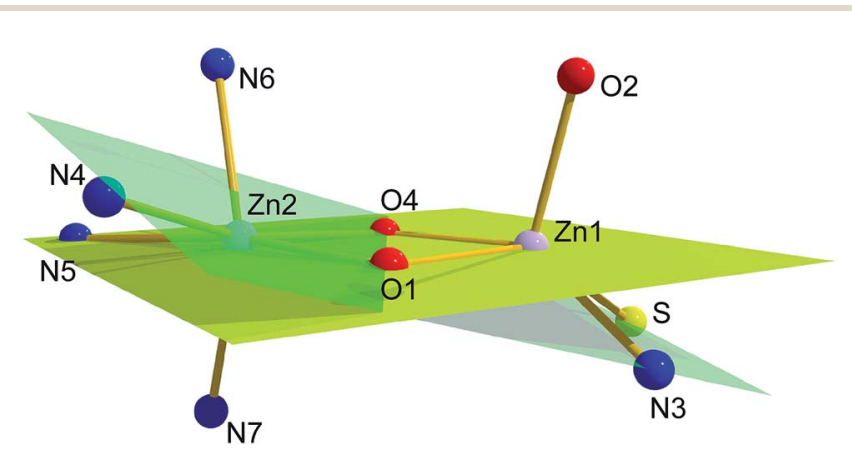

Fig. 10 Representation of the coordinations spheres of the zinc(II) ions in $\left[\mathrm{Zn}_{2}\right.$ (tsc-hydra) $\left.(\mathrm{OAc})_{2}\right]$. The two depicted planes contain the common $\mathrm{O} 1-\mathrm{O} 4$ axis as hinge and correspond to the mean planes given by the $(\mathrm{O} 1, \mathrm{O} 4, \mathrm{~N} 5)$ and $(\mathrm{S}, \mathrm{O} 1, \mathrm{O} 4, \mathrm{~N} 3)$ which create an angle of about $20^{\circ}$. Pertinent distances from planes (in pm): (O1, O4, N5) Zn2 12.8, N4 75.0; (S, O1, O4, N3) Zn2 45.9, N4 22.8. 


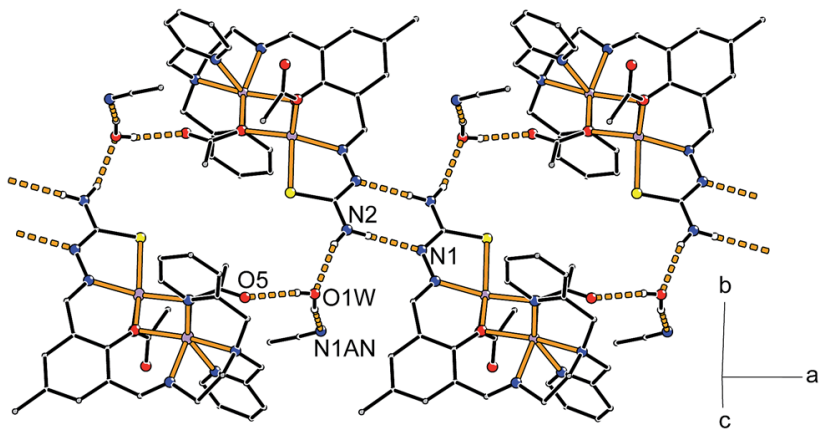

Fig. 11 Representation of the hydrogen bonding interactions in the crystal structure of $\left[\mathrm{Zn}_{2}\right.$ (tsc-hydra) $\left.(\mathrm{OAc})_{2}\right] \cdot \mathrm{MeCN} \cdot \mathrm{H}_{2} \mathrm{O}$ leading to a chain-like arrangement along the [100] direction. Pertinent distances

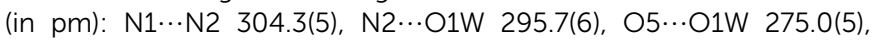

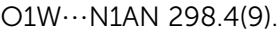

of chain-like aggregation of the complex molecules along the [100] direction as depicted in Fig. 11. Two such symmetry related chains buildup the crystal structure with relative orientations of their planar hydrogen paired ligand backbones aligned along the crystallographic (011) and (011) planes. The acetonitrile molecules are located between these chains such that they have hydrogen bonding contacts with neighboring chains of the same basic orientation (see Fig. S27†). The closest contact between chains of different orientation are $\pi-\pi$ interactions of a pyridyl ring (N7) with the central aromatic ring of an adjacent complex molecule (see Fig. S28 $\dagger$ ). Together with additional packing effects due to the acetonitrile molecule the latter interaction leads to an out-ofplane distortion of the phenolate oxygen $\mathrm{O} 1(16 \mathrm{pm})$ and the methyl group C9 (18 pm) substituents at the central aromatic ring (C3 to $\mathrm{C} 8)$.

\section{Conclusions}

A simple and straightforward synthetic approach towards unsymmetric double Schiff-base ligands on the basis of isolated intermediate mono Schiff-base precursors is presented. The first step of this synthetic route can generally be handled on a large scale when thiosemicarbazide and semicarbazide are used as amine components to generate the mono Schiff bases. These precursors can be utilized to synthesize a variety of unsymmetric end-off compartmental double Schiff-base ligands with both flexible and rigid donor sets. For two examples of the presented ligands their coordination behavior has been studied by the synthesis of appropriate metal complexes. The mono Schiff-base proligand $\mathrm{H}_{2}$ tsc-difo was used to generate a nickel(II) complex [Ni(tsc-difo) $\mathrm{PPh}_{3}$ ] with triphenylphosphane as coligand leading to a complex with squareplanar geometry at the nickel(II) center. As an example from the series of unsymmetric ditopic ligands we selected $\mathrm{H}_{2}$ tschydra due to its combination of a rigid and a flexible binding pocket. To explore its coordination behavior the homodinuclear zinc(II) complex $\left[\mathrm{Zn}_{2}\right.$ (tsc-hydra) $\left.(\mathrm{OAc})_{2}\right]$ was synthesized. Interestingly two different coordination geometries were observed for the two zinc(II) ions indicating that the two distinctly different binding pockets of the ligand can enforce specific coordination modes which could be used to deliberately coordinate metal ions with corresponding geometric preferences for their coordination sphere. A specific potential can be attributed to complexes of the proligands as it should also be possible to utilize them for subsequent derivatization towards the generation of a second binding site with otherwise not accessible combinations of the underlying amine components.

\section{Acknowledgements}

This work was in part supported by the Collaborative Research Centre ChemBioSys (CRC 1127 ChemBioSys) and funded by the Deutsche Forschungsgemeinschaft (DFG). We thank Stefan Schinkel for assistance in the assignment of the NMR data.

\section{References}

1 Handbook on Metalloproteins, ed. I. Bertini, A. Sigel and H. Sigel, Marcel Dekker, New York, 2001.

2 Handbook of Metalloproteins, ed. A. Messerschmidt, Wiley, New York, 2001-2011, vol. 1-5.

3 C. Belle, Eur. J. Inorg. Chem., 2003, 4137-4146.

4 J. J. H. Satcher, M. W. Droege, T. J. R. Weakley and R. T. Taylor, Inorg. Chem., 1995, 34, 3317-3328.

5 S. J. Lippard, Science, 1995, 268, 996-997.

6 B. Zambelli, F. Musiani, S. Benini and S. Ciurli, Acc. Chem. Res., 2011, 44, 520-530.

7 T. Palzkill, Ann. N. Y. Acad. Sci., 2013, 1277, 91-104.

8 R. E. Stenkamp, Chem. Rev., 1994, 94, 715-726.

9 N. Mitić, S. J. Smith, A. Neves, L. Guddat, L. R. Gahan and G. Schenk, Chem. Rev., 2006, 106, 3338-3363.

$10 \mathrm{~J}$. A. Tainer, E. D. Getzoff, J. S. Richardson and D. C. Richardson, Nature, 1983, 306, 284-287.

11 A. Roth and W. Plass, Angew. Chem., Int. Ed., 2008, 47, 75887591.

12 M. Carboni and J.-M. Latour, Coord. Chem. Rev., 2011, 255, 186-202.

13 S. Matsunaga and M. Shibasaki, Chem. Commun., 2014, 50, 1044-1057.

14 I. Bratko and M. Gomez, Dalton Trans., 2013, 42, 1066410681.

15 D. G. H. Hetterscheid, S. H. Chikkali, B. de Bruin and J. N. H. Reek, ChemCatChem, 2013, 5, 2785-2793.

16 T. Hellmuth, S. Rieckhoff, M. Weiss, K. Dorst, W. Frey and R. Peters, ACS Catal., 2014, 4, 1850-1858.

17 B. Wu, J. C. Gallucci, J. R. Parquette and T. V. RajanBabu, Chem. Sci., 2014, 5, 1102-1117.

18 S. W. S. Choy, M. J. Page, M. Bhadbhade and B. A. Messerle, Organometallics, 2013, 32, 4726-4729.

19 D. C. Powers and T. Ritter, Acc. Chem. Res., 2012, 45, 840-850.

20 M. Delferro and T. J. Marks, Chem. Rev., 2011, 111, 24502485.

21 J. P. McInnis, M. Delferro and T. J. Marks, Acc. Chem. Res., 2014, 47, 2545-2557. 
22 P. A. Vigato and S. Tamburini, Coord. Chem. Rev., 2004, 248, 1717-2128.

23 P. A. Vigato, V. Peruzzo and S. Tamburini, Coord. Chem. Rev., 2012, 256, 953-1114.

24 D. E. Fenton and H. Okawa, Chem. Ber./Recl., 1997, 130, 433442.

25 A. L. Gavrilova and B. Bosnich, Chem. Rev., 2004, 104, 349383.

26 P. J. Steel, Acc. Chem. Res., 2005, 38, 243-250.

27 M. Jarenmark, H. Carlsson and E. Nordlander, C. R. Chim., 2007, 10, 433-462.

28 P. A. Vigato and S. Tamburini, Coord. Chem. Rev., 2008, 252, 1871-1995.

29 K. E. Dalle and F. Meyer, Eur. J. Inorg. Chem., 2015, 33913405.

30 G. Belle, G. Gellon, C. Scheer and J.-L. Pierre, Tetrahedron Lett., 1994, 35, 7019-7022.

31 M. Suzuki, S. Fujinami, T. Hibino, H. Hori, Y. Maeda, A. Uehara and M. Suzuki, Inorg. Chim. Acta, 1998, 283, 124-135.

32 T. Koga, H. Furutachi, T. Nakamura, N. Fukita, M. Ohba, K. Takahashi and H. Ōkawa, Inorg. Chem., 1998, 37, 989-996.

33 D. E. Fenton, Chem. Soc. Rev., 1999, 28, 159-168.

34 R. Than, A. A. Feldmann and B. Krebs, Coord. Chem. Rev., 1999, 182, 211-241.

35 H. Adams, L. R. Cummings, D. E. Fenton and P. E. McHugh, Inorg. Chem. Commun., 2003, 6, 19-22.

36 Y. Tachi, K. Aita, S. Teramae, F. Tani, Y. Naruta, S. Fukuzumi and S. Itoh, Inorg. Chem., 2004, 43, 4558-4560.

37 R. A. Peralta, A. Neves, A. J. Bortoluzzi, A. Casellato, A. dos Anjos, A. Greatti, F. R. Xavier and B. Szpoganicz, Inorg. Chem., 2005, 44, 7690-7692.

38 M. F. Anderlund, J. Högblom, W. Shi, P. Huang, L. Eriksson, H. Weihe, S. Styring, B. Åkermark, R. Lomoth and A. Magnuson, Eur. J. Inorg. Chem., 2006, 5033-5047.

39 Y.-W. Ren, J.-X. Lu, B.-W. Cai, D.-B. Shi, H.-F. Jiang, J. Chen, D. Zheng and B. Liu, Dalton Trans., 2011, 40, 1372-1381.

40 M. Jarenmark, M. Haukka, S. Demeshko, F. Tuczek, L. Zuppiroli, F. Meyer and E. Nordlander, Inorg. Chem., 2011, 50, 3866-3887.

41 G. N. Ledesma and S. R. Signorella, Tetrahedron Lett., 2012, 53, 5699-5702.

42 L. J. Daumann, L. Marty, G. Schenk and L. R. Gahan, Dalton Trans., 2013, 42, 9574-9584.

43 D. Wang, S. V. Lindeman and A. T. Fiedler, Inorg. Chim. Acta, 2014, 421, 559-567.

44 B. Das, H. Daver, M. Pyrkosz-Bulska, E. Persch, S. K. Barman, R. Mukherjee, E. Gumienna-Kontecka, M. Jarenmark, F. Himo and E. Nordlander, J. Inorg. Biochem., 2014, 132, 6-17. 45 K. C. Gupta and A. K. Sutar, Coord. Chem. Rev., 2008, 252, 1420-1450.

46 A. W. Kleij, Eur. J. Inorg. Chem., 2009, 193-205.

47 A. Roth, E. T. Spielberg and W. Plass, Inorg. Chem., 2007, 46, 4362-4364.

48 A. Roth, A. Buchholz, M. Rudolph, E. Schütze, E. Kothe and W. Plass, Chem.-Eur. J., 2008, 14, 1571-1583.
49 M. Ciaccia, S. Pilati, R. Cacciapaglia, L. Mandolini and S. D. Stefano, Org. Biomol. Chem., 2014, 12, 3282-3287.

50 T. S. Lobana, R. Sharma, G. Bawa and S. Khanna, Coord. Chem. Rev., 2009, 253, 977-1055.

51 P. J. Jansson, P. C. Sharpe, P. V. Bernhardt and D. R. Richardson, J. Med. Chem., 2010, 53, 5759-5769.

52 D. R. M. Moreira, A. D. T. de Oliveira, P. A. T. de Moraes Gomes, C. A. de Simone, F. S. Villela, R. S. Ferreira, A. C. da Silva, T. A. R. dos Santos, M. C. A. B. de Castro, V. R. A. Pereira and A. C. L. Leite, Eur. J. Med. Chem., 2014, 75, 467-478.

53 L. Blau, R. F. Menegon, G. H. G. Trossini, J. V. D. Molino, D. G. Vital, R. M. B. Cicarelli, G. D. Passerini, P. L. Bosquesi and C. M. Chin, Eur. J. Med. Chem., 2013, 67, 142-151.

54 L. F. Lindoy, G. V. Meehan and N. Svenstrup, Synthesis, 1998, 1029-1032.

55 M. Schatz, M. Leibold, S. P. Foxon, M. Weitzer, F. W. Heinemann, F. Hampel, O. Walter and S. Schindler, Dalton Trans., 2003, 8, 1480-1487.

56 R. W. W. Hooft, COLLECT, Data Collection Software, Nonius BV, Delft, Netherlands, 1998.

57 Z. Otwinowski and W. Minor, in Methods in Enzymology, Macromolecular Crystallography, Part A, ed. C. W. Carter and R. M. Sweet, Academic Press, New York, 1997, vol. 276, pp. 307-326.

58 SADABS 2.10, Bruker-AXS Inc., Madison, Wisconsin, USA, 2002.

59 G. M. Sheldrick, Acta Crystallogr., Sect. A: Found. Crystallogr., 2008, 64, 112-122.

60 L. Sobczyk, S. J. Grabowski and T. M. Krygowski, Chem. Rev., 2005, 105, 3513-3560.

61 P. Gilli, V. Bertolasi, V. Ferretti and G. Gilli, J. Am. Chem. Soc., 2000, 122, 10405-10417.

62 J. S. Casas, M. S. García-Tasende and J. Sordo, Coord. Chem. Rev., 2000, 209, 197-261.

63 T. S. Lobana, R. Sharma, G. Bawa and S. Khanna, Coord. Chem. Rev., 2009, 253, 977-1055.

64 R. Alonso, E. Bermejo, A. Custiñeiras, T. Pérez and R. Carballo, Z. Anorg. Allg. Chem., 1997, 623, 818-824.

65 H. Günther, NMR Spectroscopy, Wiley-VCH, Weinheim, 3rd edn, 2013.

66 K. G. Orrell, A. G. Osborne, J. O. Prince, V. Šik and D. K. Vellianitis, Eur. J. Inorg. Chem., 2000, 2000, 383-391.

67 A. B. P. Lever, Inorganic Electronic Spectrocopy, Elsevier, Amsterdam, 2nd edn, 1984.

68 V. Philip, V. Suni, M. R. P. Kurup and M. Nethaji, Polyhedron, 2004, 23, 1225-1233.

69 N. T. Akinchan, R. Akinchan, U. J. Ibok, L. P. Battaglia, A. Bonamartini Corradi and P. Drozdzewski, J. Crystallogr. Spectrosc. Res., 1992, 22, 741-753.

70 T. S. Lobana, P. Kumari, G. Hundal and R. J. Butcher, Polyhedron, 2010, 29, 1130-1136.

71 R. Prabhakaran, P. Kalaivani, P. Poornima, F. Dallemer, G. Paramaguru, V. V. Padma, R. Renganathan, R. Huang and K. Natarajan, Dalton Trans., 2012, 41, 9323-9336. 
72 O. Kühl, in The Range of Chemical Shifts, Coupling Constants, and What Influences Each, ed. O. Kühl, Springer-Verlag, Berlin Heidelberg, 2008, ch. 2, pp. 7-23.

73 L. Pazderski, Annu. Rep. NMR Spectrosc., 2013, 80, 33-179.

74 T. Steiner and G. Koellner, J. Mol. Biol., 2001, 305, 535-557.
75 O. Takahashi, Y. Kohno and M. Nishio, Chem. Rev., 2010, 110, 6049-6076.

76 W. Plass, Z. Anorg. Allg. Chem., 1997, 623, 461-477.

77 W. Plass, Z. Anorg. Allg. Chem., 1994, 620, 1635-1644.

78 J. B. Mandel, C. Maricondi and B. E. Douglas, Inorg. Chem., 1988, 27, 2990-2996. 